\title{
Addressing the patient experience in myocardial perfusion scintigraphy
}

\author{
Ana M Grilo ${ }^{1,2 *}$, Lina Vieira ${ }^{3}$, Elisabete Carolino ${ }^{3}$, Jéssica Ferreira ${ }^{1}$ and Maria Neves ${ }^{1}$ \\ ${ }^{1}$ ESTeSL- Escola Superior de Tecnologia da Saúde, Instituto Politécnico de Lisboa. Av. D. João II, lote 4.69.01, Parque das Nações, 1990-096 Lisboa, Portugal \\ ${ }^{2}$ Centro de Investigação em Ciência Psicológica, Faculdade de Psicologia, Universidade de Lisboa, Alameda da Universidade, 1649-013 Lisboa, Portugal \\ ${ }^{3}$ H\&TRC-Centro de Investigação em Saúde e Tecnologia, ESTeSL-Escola Superior de Tecnologia da Saúde, Instituto Politécnico de Lisboa. Av. D. João II, lote \\ 4.69.01, Parque das Nações, 1990-096 Lisboa, Portugal
}

\begin{abstract}
Background: Myocardial Perfusion Scintigraphy is a medical exam whose purpose is to evaluate myocardial perfusion. This examination due to their procedures can generate some anxiety in patients that can disturb the good performance of the exam. The main objective of this study is to perform an analysis of patient s undergoing myocardial perfusion scintigraphy experience, assess patient`s anxiety and check Nuclear Medicine Department communication and information effectiveness.
\end{abstract}

Material and methods: For this study, State-Trait Anxiety Inventory (STAI) and two Scan Experience Questionnaires were used. Sixty patients answered the questionnaires before and after myocardial perfusion scintigraphy.

Results: Patients reported medium levels of scan-related anxiety before the myocardial perfusion scintigraphy. After the scan, there is a slight decrease in patients anxiety. Results of the scan, radiation used, duration of the scan and the injection of the radiopharmaceutical are the most relevant patients concerns before the scan. $15 \%$ of the sample did not receive the necessary information or the most effective way.

Conclusions: The results suggest that there are several factors that tend to trigger patient`s experience and anxiety. Strategies to improve patient myocardial perfusion scintigraphy experience at Nuclear Medicine Department are presented.

\section{Introduction}

Myocardial Perfusion Scintigraphy (MPS) is a procedure whose purpose is to evaluate myocardial perfusion. This scan consists of two phases (stress and rest), in which images of the myocardium are acquired and the patient needs to be in the same position (in dorsal decubitus with the arms in hyperextension above the head), an average of 10 to 20 minutes [1].

In terms of acquired image, the most common artifacts are patient movement (a small movement is enough for the exam to be repeated, and it may also generate false positives). This movement can have several causes as the anxiety, discomfort of the positioning, the fatigue before the scan made and certain physical conditions like arthritis $[2,3]$.

When a patient is proposed to perform a nuclear medicine (NM) procedure, it tends to create anxiety. Anxiety is a state of agitation, worry or anguish, which creates states of fear, vigilance, and stress in the human being [4]. Whenever a person is confronted with a new situation, which gives a different or unknown experience, it tends to generate fear, especially if there is an association with pain. The greater the anxiety, the greater the susceptibility of hospital time to become a negative experience $[5,6]$.

The Spielberger [7] model argues that the state of anxiety can be considered as a transient emotional state that varies in intensity and durability in function of the subject's perception of the threat. It is the cognitive function of the subject that determines whether a given stimulus is perceived as dangerous or threatening.
Some studies indicate that early life experiences, under certain conditions, contribute to a psychological vulnerability to experiencing anxiety and negative affective states. Thus, it is assumed that it is important to study and understand stress, as stress can affect health through behavioral or physiological changes [7].

In the literature, there is little information on the anxiety and experience of the patient undergoing MPS [8]. With this study we intend to assess patients' anxiety before and after the scan, evaluate the patients' scan experience and check Nuclear Medicine Department communication and information effectiveness.

\section{Methodology}

This study is a part of a larger research project to addressing the patient experience in medical image exams conducted in departments of radiology and NM of a Hospital in Lisbon. Hospital ethical committee approved the study. A cross-sectional prospective study was achieved with patients who have a clinical indication to perform MPS at an NM department.

${ }^{*}$ Correspondence to: Ana M Grilo, ESTeSL-Escola Superior de Tecnologia da Saúde, Instituto Politécnico de Lisboa. Av. D. João II, lote 4.69.01, Parque das Nações, 1990-096 Lisboa, Portugal, E-mail: ana.grilo@estesl.ipl.pt

Key words: patient experience, myocardial perfusion scintigraphy, anxiety, concerns, information provided

Received: January 7, 2019; Accepted: February 04, 2019; Published: February 08, 2019 
Data collection initiated after eligible patients were informed of the purpose of the study. Once the patients' signed the informed consent the pre-scan-questionnaire were given. Patients finished the entire scan and then post-questionnaire was provided.

\section{Participants}

The sample included 60 patients. All patients underwent MPS at the same clinical center under the same conditions (some patients underwent pharmacological stress tests and others with physical exercise tests). The non-probabilistic sample included individuals over or equal to 18 the age of eighteen, with cognitive ability to answer questions.

The exclusion criteria were patients who could not cooperate, illiterate patients, patients who had failed in completed the questionnaire.

\section{Assessment instruments}

Patients filled out two questionnaires:

Pre-Scan questionnaire includes personal information (age, gender, literacy), knowledge about the type of scan to be carried out, subjective perception of anxiety, scan related main concerns and the State-Trait Anxiety Inventory-Trait (STAI-T) and State (STAI-S).

Pos-Scan questionnaire contains questions about the scan experience (comfort, safety, etc), the perception of NM Department communication and information provided and a STAI-S.

The Spielberger State-Trait Anxiety Inventory (STAI) [7] is answered using a Likert scale, ranging from 1 to 4 . The STAI-S comprises 20 items, in which the patient's emotional state (in the moment) is assessed. The STAI-T form also contains 20 items in which the patient's emotional state is generally assessed. The higher the final scores, the higher the level of anxiety.

\section{Data analysis}

The data were analyzed in the statistical software SPSS, version 22.0 for Windows.

To test the normality of the data, the Kolmogorov-Smirnov test was used. The results were considered significant at the $5 \%$ significance level. Quantitative variables were presented as means and standard deviation. Spearman's rank correlation was used, to measure the degree of association between two variables (literacy and the pre-scan questionnaire STAI-S) and Pearson's correlation most widely used correlation statistic to measure the degree of relationship between linearly related relationships (age and pre-scan questionnaire STAI-S). To compare the anxiety state between pre and post examination, the $t$ test was used, once the normality assumption was verified.

\section{Results}

Of 60 patients (mean age $64 \pm 9.6$ years) who completed the questionnaires, 26 were female and 34 were male. Most of the patients complete secondary or higher education. Regarding the patient's knowledge about the MPS to be performed, $20 \%$ of the sample did not know the name of the scan, and of the $80 \%$ who said they knew, many $(n=41,1 \%)$ have not adequately identified the name of the scan (Table 1).

Table 2 shows that results of the scan $(4.0 \pm 2.1)$, radiation used $(3.5 \pm 2.1)$, the time needed to perform the scan $(3.4 \pm 2.1)$, and the injection of the radiopharmaceutical $(3.3 \pm 2.1)$ are the most relevant patients' concerns before the MPS scan.

\section{Patients' MPS experience}

Patients' evaluation of the information provided by NM department was quantified on a scale of 1 to 7 . Only responses below to level 5 were obtained (the scale grows negatively) (Table 3 ).

Patients' appraised their scan experience through a scale of 1 to 7 , where the increase in scale is an indicator of negativity. A large percentage of the sample described the scan positively, and the main negative aspects found on the scan were very tiring, difficult and uncomfortable (Table 4).

\section{Patients` anxiety before and after MPS}

Patients answered a subjective perception of pre-scan anxiety through a seven-point Likert scale (1 represented Very Quiet and 7 Very Nervous). $45 \%$ of the patients show levels of anxiety equal or greater than 4 (Table 5).

There is no correlation with the increase in the degree of anxiety in age $(\mathrm{r}=-0.086, \mathrm{p}=0.513)$. A correlation of weak intensity in the negative $(\mathrm{rS}=-0.264, \mathrm{p}=0.045)$ direction was found with the educational

Table 1. Sociodemographic data and patients` knowledge and experience about the MPS $(\mathrm{n}=60)$

\begin{tabular}{|c|c|c|}
\hline \multicolumn{1}{|c|}{ Variables } & $\mathbf{n}(\mathbf{\%})$ \\
\hline \multirow{4}{*}{$\begin{array}{c}\text { Literary } \\
\text { Abilities }\end{array}$} & Without qualifications & $1(1,7 \%)$ \\
\cline { 2 - 3 } & Mandatory education & $21(36,2 \%)$ \\
\cline { 2 - 3 } & Secondary education & $16(27,6 \%)$ \\
\cline { 2 - 3 } & Higher education & $16(27,6 \%)$ \\
\cline { 2 - 3 } & Master's degree & $4(6,9 \%)$ \\
\cline { 2 - 3 } & PhD & 0 \\
\hline \multirow{2}{*}{ Gender } & Female & $26(43.3 \%)$ \\
\hline \multirow{2}{*}{$\begin{array}{c}\text { Do you know the name of } \\
\text { the scan you are going to take? }\end{array}$} & Male & $34(56,7 \%)$ \\
\hline \multirow{2}{*}{$\begin{array}{c}\text { Is this your first time } \\
\text { taking this scan? }\end{array}$} & Yes & $48(80 \%)$ \\
\cline { 2 - 3 } & No & $12(20 \%)$ \\
\hline
\end{tabular}

Table 2. Patient's main concerns before the MPS scan

\begin{tabular}{|l|c|c|c|}
\hline Patients` Concerns & Mean \pm SD & Minimum & Maximum \\
\hline Radiation involved & $3.5 \pm 2.1$ & 1 & 7 \\
\hline Not knowing the purpose of the exam & $2.8 \pm 2.1$ & 1 & 7 \\
\hline Immobilization/positioning & $2.8 \pm 1.7$ & 1 & 7 \\
\hline Exam Result (diagnostic) & $4.0 \pm 2.1$ & 1 & 7 \\
\hline Duration of the procedure. & $3.4 \pm 2.1$ & 1 & 7 \\
\hline Possible discomfort/pain during the scan & $3.1 \pm 2.0$ & 1 & 7 \\
\hline Lack of knowledge about the procedure & $3.1 \pm 1.9$ & 1 & 7 \\
\hline Body exposure during the scan & $2.3 \pm 1.6$ & 1 & 7 \\
\hline Injection of the radiopharmaceutical & $3.3 \pm 2.1$ & 1 & 7 \\
\hline
\end{tabular}

Table 3. Patient's evaluation of the information provided by NM department

\begin{tabular}{|l|c|c|c|c|c|}
\hline \multirow{2}{*}{ Information provided } & $\mathbf{1 . 0}$ & $\mathbf{2 . 0}$ & $\mathbf{3 . 0}$ & $\mathbf{4 . 0}$ & $\mathbf{5 . 0}$ \\
\cline { 2 - 6 } & \multicolumn{5}{|c|}{ Frequency \% } \\
\hline Understanding & $78.3 \%$ & $16.7 \%$ & $1.7 \%$ & $1.7 \%$ & $1.7 \%$ \\
\hline Utility & $71.7 \%$ & $16.7 \%$ & $8.3 \%$ & $1.7 \%$ & $1.7 \%$ \\
\hline Amount & $70.0 \%$ & $20.0 \%$ & $5.0 \%$ & $5.0 \%$ & $0.0 \%$ \\
\hline $\begin{array}{l}\text { Feel free to ask questions to } \\
\text { professionals before the scan }\end{array}$ & $83.3 \%$ & $15.0 \%$ & $0.0 \%$ & $1.7 \%$ & $0.0 \%$ \\
\hline
\end{tabular}


qualifications and the degree of anxiety. That is, the lower the literary rating, the higher the patient's level of anxiety.

Table 6 shows the mean values of the STAI-S scores pre and postscan and the STAI-T pre-scan. STAI-S pre-scan presents the greater level. There was a significant decrease in the anxiety state from pre to post $\operatorname{scan}(\mathrm{t}(59)=3.142, \mathrm{p}=0.003)$.

A correlation of moderate intensity in the positive direction was found with the STAI-S pre-scan and the STAI-S pos scan $(r=0.392$, $\mathrm{p}=0.002$ ).

\section{Discussion}

The main objective of this study is to address the patient experience in MPS and assess patient's anxiety before and after the scan.

Patients show middle levels of state anxiety before the scan. Similar results were found with patients undergoing colposcopy [10] and chemotherapy [11]. There is a slight decrease in the state of anxiety after the procedure, but patients who feel more anxious before the scan, also tend to experience more anxiety after completed the MPS scan.

Patients` concerns that may increase state anxiety before the scan were the scan procedure (e.g., radiation, radiopharmaceutical injection, duration of the scan and the waiting time before image acquisition) and the results of the scan.

MPS it is a little-recognized exam [2]. It is not a habit to perform as much as an $\mathrm{x}$-ray, and most of the patients do not know what to

Table 4. Patients`scan experience and emotions after the procedure

\begin{tabular}{|l|l|l|l|l|l|l|l|}
\hline Describe the scan in terms of & $\mathbf{1 . 0}$ & $\mathbf{2 . 0}$ & $\mathbf{3 . 0}$ & $\mathbf{4 . 0}$ & $\mathbf{5 . 0}$ & $\mathbf{6 . 0}$ & $\mathbf{7 . 0}$ \\
\cline { 2 - 8 } & Frequency \% & \multicolumn{3}{|l|}{} \\
\hline Facility & $55.0 \%$ & $20.0 \%$ & $10.0 \%$ & $8.3 \%$ & $0.0 \%$ & $3.3 \%$ & $3.3 \%$ \\
\hline Comfort & $35.0 \%$ & $30.0 \%$ & $10.0 \%$ & $8.3 \%$ & $10.0 \%$ & $3.3 \%$ & $3.3 \%$ \\
\hline Control & $63.3 \%$ & $21.7 \%$ & $3.3 \%$ & $10.0 \%$ & $0.0 \%$ & $0.0 \%$ & $1.7 \%$ \\
\hline No Claustrophobia & $70.0 \%$ & $18.3 \%$ & $5.0 \%$ & $1.7 \%$ & $1.7 \%$ & $0.0 \%$ & $3.3 \%$ \\
\hline Without Pain & $76.7 \%$ & $11.7 \%$ & $3.3 \%$ & $3.3 \%$ & $1.7 \%$ & $3.3 \%$ & $0.0 \%$ \\
\hline Positive Experience & $55.0 \%$ & $23.3 \%$ & $13.3 \%$ & $6.7 \%$ & $0.0 \%$ & $1.7 \%$ & $0.0 \%$ \\
\hline Without Fatigue & $55.0 \%$ & $23.3 \%$ & $8.3 \%$ & $3.3 \%$ & $1.7 \%$ & $1.7 \%$ & $6.7 \%$ \\
\hline How you feel after the scan & & & & & & & \\
\hline Safe & $80.0 \%$ & $6.7 \%$ & $8.3 \%$ & $1.7 \%$ & $1.7 \%$ & $1.7 \%$ & $0.0 \%$ \\
\hline Calm & $76.7 \%$ & $10.0 \%$ & $1.7 \%$ & $6.7 \%$ & $0.0 \%$ & $3.3 \%$ & $1.7 \%$ \\
\hline No doubts & $70.0 \%$ & $10.0 \%$ & $13.3 \%$ & $1.7 \%$ & $0.0 \%$ & $3.3 \%$ & $1.7 \%$ \\
\hline Staff Support & $80.0 \%$ & $13.3 \%$ & $1.7 \%$ & $1.7 \%$ & $3.3 \%$ & $0.0 \%$ & $0.0 \%$ \\
\hline Relieve & $70.0 \%$ & $16.7 \%$ & $1.7 \%$ & $3.3 \%$ & $3.3 \%$ & $3.3 \%$ & $1.7 \%$ \\
\hline
\end{tabular}

Table 5. Self-assessment of anxiety before the scan

\begin{tabular}{|c|c|c|}
\hline Scale & Frequency (N) & Percent (\%) \\
\hline 1.0 & 9 & 15.0 \\
\hline 2.0 & 13 & 21.7 \\
\hline 3.0 & 11 & 18.3 \\
\hline 4.0 & 14 & 23.3 \\
\hline 5.0 & 9 & 15.0 \\
\hline 6.0 & 3 & 5.0 \\
\hline 7.0 & 1 & 1.7 \\
\hline
\end{tabular}

Table 6. STAI State and Trait descriptive statistics

\begin{tabular}{|l|c|c|c|}
\hline & Mean \pm SD & Minimum & Maximum \\
\hline STAI-T (pre scan) & $47.6 \pm 5.8$ & 34 & 62 \\
\hline STAI-S (pre scan) & $48.7 \pm 7.2$ & 28 & 64 \\
\hline STAI-S (post scan) & $46.6 \pm 6.9$ & 29 & 64 \\
\hline
\end{tabular}

SD: Standard deviation expect. It was found that patients who performed MPS showed a lack of knowledge about the procedure. Nowadays it is presumed that the population of different age groups have access and/or information about the medical image exam they are going to carry out, however, this seems an untruthful assumption [12]. This fact is supported by this study, in which the patients demonstrated a lack of knowledge and consequently interest in obtaining more information on certain subjects, such as the preparation of the scan and its duration.

Compared to other nuclear medicine scans, MPS is a timeconsuming scan such as the thyroid exam. This procedure is performed in two different stages, which requires a time interval between them (the interval allows the patient's physiological conditions to be within the parameters for image acquisition) [1]. This factor tends to create anxiety in the patients related to possible changes that must be made in their personal life and due to the position, they must maintain during the acquisition time [2].

On the other hand, many people are afraid or uncomfortable with injections, vaccines or needles [13]. Just as few people are aware of what the radiopharmaceutical is, what it generates and what it causes in the body. Other factors such as the proximity of the detectors during the acquisition of the image can lead to a loss of sensation of control and feelings of claustrophobia and, consequently, fear of getting hurt. The combination of these conditions may lead to less positive patient experience and lack of cooperation on the part of the patient [2].

Regarding patients concerns about scan results, it must be noted that MPS is specified to evaluate myocardial perfusion. Therefore, negative results carriage a threat to the person's lifestyle and even to life itself [14].

Although the patients who underwent MPS classifies the information provided by the service as accessible and useful, the data also shows that the information is not completely understood, and that the quantity is not adequate. Recently Tugwell, Goulden, Mullins [15] found that the information provides to MRI patients in an appointment letter did not include adequate information to fulfilled patient needs. This means that it is necessary to review and modify the means of communication used, so that there is a more effective transmission of information.

In order to improve the information that is given to the patient, it is important that $\mathrm{MN}$ service provide written educational material about the scan, that included the equipment and details about the procedure. Another option could be the creation of a website with informative and interactive video, without technical language and that can be presented in different languages $[5,16]$.

On the day scan day, the patient entering the service should be approached by a nuclear medicine technologist (NMT), who would accompany him throughout the examination, explaining the whole procedure and answering any questions that may arise. It is important that is the same professional throughout the exam, in order to create a bond of trust and to make the patient feel comfortable to express their doubts [12].

The waiting room should have distracting elements, such as tablets coupled with chairs, television, and the internet. During images acquisition music could to be an effective strategy in managing anxiety $[17,18]$ and NMT should not leave the patient alone in the room, as some patients feel more relaxed listening to the technologist' voice. 
This study had some limitations since it covered a small sample, restricted to a hospital NM department. It would be beneficial to increase the sample and introducing new parameters as MPS patients' self-efficacy related to the scan and assess patients' anxiety between the two phases of the MPS scan. Analyzing the effect of an information booklet about the scan on patients' anxiety could also be interesting.

\section{Conclusion}

The results suggest that there are several factors that tend to trigger patient's experience and anxiety concerning MPS scan. Less anxious patients are more cooperative and makes the service more efficient anda profitable. Strategies to improve patient MPS experience at Nuclear Medicine Department should be considered.

\section{Conflicts of interest}

There are no conflicts of interest.

\section{Acknowledgement}

The authors thank the Nuclear Medicine Department of Hospital CUF Descobertas for their availability and help in the delivery of the questionnaires to the patients who underwent MPS.

\section{References}

1. Underwood SR, Anagnostopoulos C, Cerqueira M, Ell PJ, Flint EJ, et al. (2004) Myocardial perfusion scintigraphy: The evidence. Eur J Nucl Med Mol Imaging 31: 261-291. [Crossref]

2. Nightingale JM, Murphy FJ, Blakeley C (2012) I thought it was just an X-ray: A qualitative investigation of patient experiences in cardiac SPECT-CT imaging. Nucl Med Commun 32: 246-254. [Crossref]

3. Barlow D (2002) Anxiety and its disorders: The nature and treatment of anxiety and panic. ( $2^{\mathrm{a}} \mathrm{Ed}$.), The Guilford Press, New York.

4. Massardo T, Jaimovich R, Faure R, Muñoz M, Alay R, et al. (2010) Motion correction and myocardial perfusion SPECT using manufacturer provided software. Does it affect image interpretation? Eur J Nucl Med Mol Imagin 37: 758-764. [Crossref]

5. Delewi R, Vlastra W, Rohling WJ, Wagenaar TC, Zwemstra M, et al. (2017) Anxiety levels of patients undergoing coronary procedures in the catheterization laboratory. Int J Cardiol 228: 926-930. [Crossref]
6. Munn Z, Jordan Z (2014) The effectiveness of nonpharmacologic interventions to reduce anxiety and increase patient satisfaction and comfort during nuclear medicine imaging. J Med Imaging Radiat Sci 45: 47-54.

7. Spielberger C, Gorsuch R, Lushene R (1982) Manual del Cuestionario Ansiedad Estado/Rasgo (STAI), TEA Ediciones, Madrid,Espa na.

8. Tamam MO, Bagcioglu E, Mulazimoglu M, Tamam L, Ozpacaci T (2012) Evaluation of anxiety and depression in patients prior to myocardial perfusion scintigraphy. Int $J$ Psychiatry Clin Pract 16: 93-97.

9. Silva D (2003) O inventario de estado - traço de ansiedade (STAI). In: Avaliacão Psicológica: Instrumentos Validados Para a ' População Portuguesa, M. Gonçalves, Ed, Quarteto Editora, Coimbra, Portugal, pp: 45-63.

10. Kola S, Walsh JC (2012) Determinants of pre-procedural state anxiety and negative affect in first-time colposcopy patients: Implications for intervention. Eur J Cancer Care (Engl) 21: 469-476. [Crossref]

11. Schreier AM, Williams SA (2004) Anxiety and quality of life of women who receive radiation or chemotherapy for breast cancer. Oncol Nurs Forum 31: 127-130. [Crossref]

12. Halkett GK, Kristjanson LJ, Lobb E, Little J, Taylor TM, et al. (2012) Information needs and preferences of women as they proceed through radiotherapy for breast cancer. Patient Educ Couns 86: 396-404. [Crossref]

13. Wright S, Yelland M, Heathcote K, Ng SK, Wright G (2009) Fear of needles--nature and prevalence in general practice. Aust Fam Physician 38: 172-176. [Crossref]

14. Mugeoner T, Erman B, Mehmet M, Tamam L, Ozpacaci Tevfik O (2012) Evaluation of anxiety and depression in patients prior to myocardial perfusion scintigraphy. Int $\mathrm{J}$ Psychiatry Clin Pract 16: 93-97. [Crossref]

15. Tugwell JR, Goulden N, Mullins P (2018) Alleviating anxiety in patients prior to MRI: A pilot single-center single-blinded randomized controlled trial to compare video demonstration or telephone conversation with a radiographer versus routine intervention. Radiography 24: 122-129. [Crossref]

16. Ahlander BM, Engvall J, Maret E, Ericsson E (2018) Positive effect on patient experience of video-information given prior to cardiovascular magnetic resonance imaging, a clinical trial. J Clin Nurs 27: 1250-1261. [Crossref]

17. Buffum MD, Sasso C, Sands LP, Lanier E, Yellen M, et al. (2006) A music intervention to reduce anxiety before vascular angiography procedures. J Vasc Nurs 24: 68-73. [Crossref]

18. Lee W, Sung H, Liu S, Chang S (2017) Meditative music listening to reduce state anxiety in patients during the uptake phase before positron emission tomography (PET) scans. Br J Radiol 90: 20160466. [Crossref]

Copyright: (C)2019 Grilo AM. This is an open-access article distributed under the terms of the Creative Commons Attribution License, which permits unrestricted use, distribution, and reproduction in any medium, provided the original author and source are credited. 